Wolfgang Sterk, Hans Bolscher, Jeroen van der Laan, Jelmer Hoogzaad \& Jos Sijm

\title{
Developing a sectoral new market mechanism: insights from theoretical analysis and country showcases
}

This is an Accepted Manuscript of an article published by Taylor \& Francis Group in Climate Policy on 23/07/2014, available online:

http://www.tandfonline.com/doi/abs/10.1080/14693062.2014.937384 
Wolfgang Sterk ${ }^{a,}{ }^{,}$, Hans Bolscher ${ }^{b}$, Jeroen van der Laan ${ }^{b}$, Jelmer Hoogzaad ${ }^{c} \&$ Jos Sijm ${ }^{d}$

\section{Developing a sectoral new market mechanism: insights from theoretical analysis and country showcases}

a Wuppertal Institute für Climate, Environment and Energy, Wuppertal, Germany

b Triple E Consulting, Rotterdam, The Netherlands

${ }^{\mathrm{C}}$ Climate Focus, Amsterdam, The Netherlands

${ }^{d}$ Energy Research Centre of the Netherlands (ECN), Amsterdam, The Netherlands

* Corresponding author: Wolfgang Sterk, Wuppertal Institute für Climate, Environment and Energy, Döppersberg 19, 42103 Wuppertal, Germany

E-mail: wolfgang.sterk@wupperinst.org

Phone: +49202 2492149

Fax: +492022492250 


\title{
Developing a Sectoral New Market Mechanism - Insights from Theoretical Analysis and Country Showcases
}

\begin{abstract}
:
Parties to the United Nations Framework Convention on Climate Change (UNFCCC) have decided to establish a "new market-based mechanism" (NMM) to promote mitigation across "broad segments" of developing countries' economies but have so far defined only some broad outlines of how it is to function. This article identifies key design options of the NMM based on a survey of the literature and reviews them against a range of assessment criteria. Furthermore, potential application of the NMM is analysed for five country-sector combinations. The analysis finds that lack of data and of institutions that could manage the NMM are key bottlenecks. In addition, the analysis reveals the existence of substantial no-regret reduction potential, suggesting that sectors may not be sensitive to the market incentives from an NMM. Governmental capacity building and nationally appropriate mitigation actions (NAMAs) might be more appropriate on the short term, preparing the ground for the adoption of market-based approaches at a later stage. NMM pilots could be based on supported NAMAs but should ideally generate tradable and compliance-grade emission credits in order to fully simulate the real-life conditions of an NMM.
\end{abstract}

\section{Policy Relevance:}

The Doha conference identified "possible elements" of the NMM to be addressed in the development of the NMM's modalities and procedures. This article identifies available options for these possible elements and reviews these options against a number of criteria, including environmental effectiveness, economic efficiency, political and administrative 
efficiency, and others. On this basis the article identifies options that are best suited to fulfil the main aims of the NMM as decided at the Durban conference, "to enhance the cost-effectiveness of, and to promote, mitigation actions". In addition, the article analysis potential application of the NMM for five country-sector combinations. The analysis assesses the emission reduction potential that could be mobilised through the NMM as well as the institutional market readiness of the sectors. Finally, the article synthesises the challenges ahead for the NMM that have emerged from the analysis and suggests possible ways forward.

\section{Key Words:}

Emission trading, flexible mechanism, sectoral targets, new market mechanism 


\section{Introduction}

The Parties to the United Nations Framework Convention on Climate Change (UNFCCC) have been discussing options for scaling up existing and/or introducing new market mechanisms (NMMs) at the sectoral level for many years. These discussions have been partly inspired by perceived weaknesses of the existing Clean Development Mechanism $(\mathrm{CDM})$. The $\mathrm{CDM}$ has been seen as a success in leveraging private sector finance and in helping build capacity for measuring, reporting and verification (MRV) of emissions and emission reductions. However, critics have complained about lengthy and costly project registration and credit issuance procedures and the weak coverage of key sectors (such as demand-side energy efficiency and transport). Furthermore, many have also been disappointed because CDM project activities have so far been concentrated in relatively few countries and regions while, for example, most of Africa has so far been bypassed. Several studies have also questioned the additionality of a large percentage of the CDM project portfolio. Due to its design as a project-based mechanism, some have also seen the $\mathrm{CDM}$ as fundamentally incapable of achieving essential structural changes as needed to effectively combat climate change (achievements and shortcomings of the CDM are for example discussed in Haya, 2009; Schneider, 2009; Spalding-Fecher et al., 2012).

The discussion on NMMs has also been driven by the desire of industrialised countries to more strongly involve the large emerging economies in the international climate protection efforts. For example, the EU has argued that keeping global temperature increase below $2^{\circ} \mathrm{C}$ as agreed in Copenhagen will require substantial deviations from currently projected emission trajectories in developing countries, and that achieving such deviations will require broadening the scope and coverage of market-based mechanisms. In the EU's view,

"a project-based system alone cannot be sufficient to pursue low-emission pathways, 
therefore new market-based mechanisms are needed to allow us to stay within the 2 degrees target." (UNFCCC, 2011, 49).

After several years of protracted discussions, in December 2011 in Durban the seventeenth Conference of the Parties (COP) to the UNFCCC decided to "define" a NMM but did not stipulate operational details (UNFCCC, 2012a). COP decisions have so far only defined some very broad outlines of the NMM. The NMM is supposed to promote mitigation across "broad segments" of developing country economies, may operate on a sectoral and/or project-specific basis, and is to achieve a net decrease and/or avoidance of greenhouse gas (GHG) emissions. The COP's Subsidiary Body for Scientific and Technological Advice (SBSTA) is tasked with developing detailed modalities and procedures (UNFCCC, 2013a).

As the challenges of sectoral approaches are largely different from those of project-based approaches, this article limits itself to the sectoral perspective. The term "sector", however, is open to interpretation and has indeed been criticised as ambiguous by some. Prag and Briner $(2012,26)$, for example, suggest to rather refer to "groups of emitters". This article nevertheless uses the term sector as it is the term that has been established in this discussion context. But the term is used here in a generic sense, as boundaries of NMM coverage may indeed be drawn in various ways, as discussed in this article.

While COP decisions have so far remained vague due to political differences among Parties, the issue as such is not new and undefined. As evidenced in their submissions, the views of many Parties are much more elaborate than has so far been reflected in COP decisions (see e.g. UNFCCC 2012b, summarised and analysed in IGES, 2012; Sterk, 2012; UNFCCC, 2012c). In addition to discussions among Parties, researchers have discussed possibilities for scaling up the CDM to the sectoral level or creating a new sectoral 
mechanism for more than ten years already and there is hence a very rich literature on options for sectoral carbon market mechanisms (see e.g. Samaniego and Figueres, 2002; Sterk and Wittneben, 2006; Schmidt et al., 2008; Baron et al., 2009; Meckling and Chung, 2009; Schneider and Cames, 2009; Butzengeiger et al., 2010; Helme et al., 2010; Bolscher et al., 2012).

This article aims to contribute to the discussion on further development of the NMM. There are two core sets of challenges that need to be overcome. First, Parties need to agree on core design elements of the NMM. To support the political discussion the article identifies key design options for the NMM based on a survey of the literature and assesses these options against a range of assessment criteria. Based on this assessment, the article reflects on what options would be best suited to maximise environmental effectiveness and economic efficiency, the main goals of the NMM.

The second challenge to NMM development is actual implementation. Some of the abovelisted research has cast doubts on the actual practical feasibility of sectoral mechanisms for developing countries. In addition to the discussion of design issues, the article therefore also discusses potential application of the NMM for four sectors in five countries. The analysis assesses the emission reduction potential that could be mobilised through the NMM as well as the institutional market readiness of the sectors.

Finally, the article synthesises the challenges ahead for the NMM that have emerged from the analysis and discusses possible ways forward.

\section{Overview of Key Design Elements and Options for the NMM}

This section discusses design elements that in the view of the authors would need to be covered in the modalities and procedures for the NMM. Decision 1/CP.18 includes 
"possible elements" of the NMM to be taken into account by the SBSTA in the development of the NMM's modalities and procedures (UNFCCC, 2013a, para 51):

“(a) Its operation under the guidance and authority of the Conference of the Parties;

(b) The voluntary participation of Parties in the mechanism;

(c) Standards that deliver real, permanent, additional, and verified mitigation outcomes, avoid double counting of effort and achieve a net decrease and/or avoidance of greenhouse gas emissions;

(d) Requirements for the accurate measurement, reporting and verification of emission reductions, emission removals and/or avoided emissions;

(e) Means to stimulate mitigation across broad segments of the economy, which are defined by the participating Parties and may be on a sectoral and/or projectspecific basis;

(f) Criteria, including the application of conservative methods, for the establishment, approval and periodic adjustment of ambitious reference levels (crediting thresholds and/or trading caps) and for the periodic issuance of units based on mitigation below a crediting threshold or based on a trading cap;

(g) Criteria for the accurate and consistent recording and tracking of units;

(h) Supplementarity;

(i) A share of proceeds to cover administrative expenses and assist developing country Parties that are particularly vulnerable to the adverse effects of climate change to meet the costs of adaptation;

(j) The promotion of sustainable development;

(k) The facilitation of the effective participation of private and public entities;

(l) The facilitation of the prompt start of the mechanism". 
The authors consider that some of these elements can be grouped together and that not all warrant a detailed discussion. Elements (a), (b) and (g) are in the view of the authors issues of national and international governance arrangements while elements (c), (d) and (f) are issues of emission accounting. Facilitation of effective participation (element k) is in the view of the authors a function of the adequacy of available means to stimulate action (element e). Facilitation of a prompt start (element 1) is in the view of the authors mainly an issue for the starting period of the NMM with little bearing on its core operational rules. For the CDM, Decision 17/CP.7 facilitated a prompt start by starting operation of the mechanism immediately, not waiting for the entry into force of the Kyoto Protocol, and by allowing retroactive crediting of projects starting as of the year 2000, even before the adoption of the Marrakesh Accords, which defined the modalities and procedures of the Kyoto mechanisms (UNFCCC 2002).

Supplementarity (element h), the principle that use of flexible mechanisms shall only complement and not replace domestic action by the buyer country, was subject to intense discussions during the negotiations of the Marrakesh Accords but Parties were not able to agree on a quantified definition, partly for political and partly for technical reasons (Yamin, Depledge, 2004). The authors consider that further attempts to quantitatively define supplementarity would encounter the same problems and given space limitations chose not address this issue in this article.

The authors also opted not to address element $\mathrm{j}$, the promotion of sustainable development. This issue was equally divisive during the Marrakesh negotiations and is a highly complex matter. Methodologies such as the CDM Gold Standard run to dozens of pages (The Gold Standard 2012), a discussion would thus warrant an entire article by itself and would probably be a matter for a technical body rather than the COP. 
Based on these considerations, the article discusses a set of design elements as listed in Table 1. The order of the elements is different from the list in Decision 1/CP.18. For example, the authors consider that an assessment of options for governance arrangements should be preceded by a discussion of how the mechanism is supposed to function. Based on the available literature, for several elements various sub-elements can be identified that warrant being discussed separately. Means to stimulate actions may be established nationally or internationally, and may consist of direct incentives, such as issuance of emission credits, or more indirect ones, such as possibilities for banking and borrowing. Emission accounting is a question of system boundaries, the setting of targets or reference levels and MRV provisions. The COP will also need to decide how to account for potential overlaps of the NMM and the existing CDM. However, given space limitations the discussion leaves out issues that are probably better left to be dealt with by the regulatory structure to be established in the modalities and procedures, such as details of procedures for the establishment of baselines and the MRV of emissions and/or reductions.

The grouping of elements and sub-elements is not always clear-cut. For example, temporal flexibility provisions are not only an incentive but also an accounting issue. Therefore, Table 1 does not aspire to be a definite list but only to group the issues into a workable structure for the purpose of this article.

Table 1: Structure of NMM Design Elements as Discussed in the Article

\begin{tabular}{|l|l|l|}
\hline No. & Design Element & Sub-elements and Options \\
\hline $\mathbf{1}$ & $\begin{array}{l}\text { International means to stimulate } \\
\text { mitigation actions }\end{array}$ & $\begin{array}{l}\text { Crediting or trading } \\
\text { Temporal flexibility }\end{array}$ \\
\hline $\mathbf{2}$ & $\begin{array}{l}\text { National means to stimulate mitigation } \\
\text { actions }\end{array}$ & $\begin{array}{l}\text { Government policies and measures (PAMs), installation-level crediting, or } \\
\text { binding installation targets }\end{array}$ \\
\hline $\mathbf{3}$ & Emissions accounting & $\begin{array}{l}\text { System boundaries } \\
\text { Establishment of reference levels } \\
\text { Relationship of CDM and NMM }\end{array}$ \\
\hline $\mathbf{4}$ & National governance framework & Government agencies or independent agencies \\
\hline $\mathbf{5}$ & International governance framework & $\begin{array}{l}\text { Approval by CDM Board, new regulatory body, or by the COP } \\
\text { CDM Board model or full-time professional body } \\
\text { Assessment process following CDM model or inventory review model }\end{array}$ \\
\hline
\end{tabular}




\section{Assessment of Design Options}

The following discusses the respective advantages and disadvantages of the different options. This discussion is based on seven assessment criteria, as listed in Table 2. The criteria were derived from the literature on assessing climate policy instruments but given space limitations the presentation of the findings focuses on the criteria that, in the opinion of the authors, are the most important for a specific design element. For more detailed discussions of design issues see e.g. Schneider and Cames (2009), Butzengeiger-Geyer et al. (2010), Bolscher et al. (2012).

\section{Table 2: $\quad$ Assessment criteria for evaluating design options for developing the} NMM

\begin{tabular}{|l|l|}
\hline No. & Assessment criteria \\
\hline 1 & Environmental effectiveness: the extent to which an option contributes to emission reductions \\
\hline 2 & $\begin{array}{l}\text { Environmental integrity: the extent to which an option contributes to assuring that a claimed tonne of } \\
\mathrm{CO}_{2} \text { reduction is indeed a tonne }\end{array}$ \\
\hline 3 & $\begin{array}{l}\text { Administrative feasibility, including transaction costs: the extent to which an option affects the } \\
\text { opportunity to meet the need for appropriate data, information and administrative capacity }\end{array}$ \\
\hline 4 & $\begin{array}{l}\text { Political feasibility: the extent to which an option is likely to be accepted by policy-makers and } \\
\text { stakeholders }\end{array}$ \\
\hline 5 & $\begin{array}{l}\text { Economic efficiency: the extent to which an option contributes to achieving emission reductions at the } \\
\text { lowest social cost }\end{array}$ \\
\hline 6 & $\begin{array}{l}\text { Private sector participation: the extent to which an option incentivises or enforces private sector } \\
\text { participation and investment }\end{array}$ \\
\hline 7 & $\begin{array}{l}\text { Potential impacts on competitiveness: the extent to which an option positively or negatively impacts } \\
\text { competitiveness of covered companies }\end{array}$ \\
\hline
\end{tabular}

While all seven criteria are considered important by the authors, environmental effectiveness and integrity as well as economic efficiency may be considered as most important, based on the fundamental aim of the NMM as decided by Parties in Durban, "to enhance the cost-effectiveness of, and to promote, mitigation actions" (UNFCCC, 2012a, para. 83). Therefore, each sub-section will conclude with a synthesis on which design options would be the most promising for maximising mitigation outcomes and economic efficiency. 


\subsection{Element 1: International Means to Stimulate Mitigation Actions}

\subsubsection{Crediting or Trading}

There are two basic approaches to establishing an emission market mechanism, the baseline-and-credit approach, used by the CDM and other offset mechanisms, and the capand-trade approach, used by the EU emission trading system (EU ETS) and others. In the context of developing a sector-based NMM these have usually been referred to as sectoral crediting and sectoral trading.

In sectoral crediting, a country would adopt a target for a sector and credits would be issued ex-post if emissions were subsequently reduced below the target. There would be no penalty if emissions were above the target; such targets are often referred to as "no-lose targets". The no-lose character would probably enhance the political acceptability to developing countries. However, as reaffirmed in China's latest UNFCCC submission on the NMM, especially the large emerging economies have in the past been rather negative towards any kind of sectoral approaches as they view them as a "slippery slope" that may eventually lead to binding commitments. China has therefore argued that the NMM should be project-based and similar to the CDM (UNFCCC, 2012b).

Due to the non-binding nature of sectoral crediting, there would be no certainty about the environmental effectiveness of the system. It would only lead to emission reductions if the international carbon price was sufficiently high to provide proper incentives and if the target was set at an appropriate emission level (Ward et al., 2008). Based on current pledges, the supply from the existing Kyoto mechanisms may be sufficient alone to satisfy global demand for international offsets up to 2020 (Kossoy and Guigon, 2012). Another drawback is the ex-post credit issuance, which provides limited capital flow for investments and thus is an obstacle to private sector participation and overall effectiveness. Ex-post issuance limits bankability as it entails substantial risks. Ex ante, participants 
cannot be sure whether their proposal will be approved, whether they will actually achieve the expected amount of emission reductions and which price they will receive for the credits. Relying on carbon credit revenues to make an otherwise unprofitable scheme profitable is therefore an uncertain proposition. Some critics claim that due to these reasons the CDM is hardly ever a make-or-break factor when deciding to proceed with a project and that this has been confirmed by project developers (Haya, 2009).

Furthermore, if a non-binding crediting approach is applied at a sectoral level, there may be situations where some installations successfully reduce their emissions while others do not, so that the overall sectoral target may be missed. To provide actual participation incentives, the crediting of individual installations would therefore need to be decoupled from the performance of the sector as a whole, which is discussed in more detail in section 2.2 .

In sectoral trading, a country would adopt a binding emissions target for a sector and receive tradable units ex-ante. If emissions were subsequently reduced below the target, the resulting surplus of units could be sold in the carbon market, while in case of a shortfall the country would need to buy additional units. An advantage of this approach is that a binding target gives certainty about the environmental outcome and a clear political signal to emitters, which may facilitate investments. Also, due to the ex-ante allocation of allowances, trading can be conducted right from the beginning and not only ex-post as in the case of today's CDM and the proposed sectoral crediting mechanism (ButzengeigerGeyer et al., 2010). However, the political feasibility of binding targets is probably even lower in many developing countries than sectoral crediting. While this issue is not explicitly addressed in Parties' submissions on the NMM, in the context of the negotiations on the 2015 agreement many developing countries continue to be strongly opposed to suggestions that they should adopt binding commitments (Allan et al., 2013). 
Overall, the choice between sectoral crediting and sectoral trading may not have much impact on environmental effectiveness and economic efficiency. While due to its binding nature sectoral trading would have the advantage of guaranteeing a certain emissions outcome, the risk of penalties might induce countries to adopt only weak targets. One may also consider that adopting binding targets would send a clearer signal to investors, but investment incentives would largely be determined by the stringency of the target and by how the system would be implemented domestically (see section 2.2). Bindingness does not automatically constitute environmental effectiveness, as is for example currently being demonstrated by the EU. The EU's 2012 emissions were almost 20\% below 1990 levels (EEA, 2013), so the EU's commitment in the second Kyoto period only amounts to keeping its emissions stable for the rest of the decade. And there currently is no indication that the EU will be able to agree on strengthening its target. South Korea offers an example of a target that is not binding internationally but nonetheless ambitious, the carbon price in the South Korean ETS that is to start in 2015 is projected to go well beyond $100 \mathrm{USD} / \mathrm{t}$ $\mathrm{CO}_{2}$-eq. within its first years unless price containment mechanisms are implemented (Bloomberg, 2013).

\subsubsection{Temporal Flexibility}

Choices have to be made regarding several timing issues. First, the length of the crediting/trading period. On the one hand, long periods provide more investment certainty and thus promote private sector participation and overall economic efficiency, but on the other hand short periods provide more possibilities to address design flaws which may undermine environmental or economic efficiency. The EU has tried to balance these factors in its ETS by starting with short initial periods followed by longer periods after experience had been gained. However, in addition to inherent design flaws there are always risks from exogenous uncertainties such as macroeconomic cycles. And in the international context it would probably hardly be possible to adapt countries' (sectoral) 
targets to changed circumstances once they have been adopted, as illustrated by the EU's inability to increase its target. From the environmental perspective, short periods are therefore preferable to avoid a lock-in of low ambition. Promoting economic efficiency by providing investor confidence could be addressed at the level of domestic implementation (see section 2.2).

Second, compliance flexibility can be enhanced by the option of saving credits/allowances to future periods (banking) and borrowing from future periods for use in the current period. These options enhance economic efficiency and foster carbon price stability as they allow countries and firms to smooth their emission profiles through economic cycles. Banking provides incentives for early action. Such incentives are most relevant if targets are binding, but may also be of interest if targets are non-binding, for example if the expectation is that carbon prices will increase in the future or if a government expects that it will have to adopt a binding target in the following period. However, banking also makes it more difficult to correct over-allocation/over-crediting in subsequent periods. The criteria of environmental effectiveness and economic efficiency therefore point in different directions on this issue.

Borrowing is usually frowned on from an environmental perspective as it provides incentives to delay mitigation actions and entails the risk that they may not be taken in future periods either, for example if companies go bankrupt (Boemare and Quirion, 2002). In the context of an NMM operating at government level there is also the risk that countries may decide to terminate the agreement.

\subsection{Element 2: National Means to Stimulate Mitigation Actions}

As emission targets or thresholds would be set at the sector level, the mechanism would probably have to be operated by the host country government as private entities could 
hardly take responsibility for entire sectors. This raises the question how to constitute incentives for those who are supposed to undertake the emission reduction investments. The following basic options can be conceived.

In option 1, the host country government would implement non-ETS policies and measures (PAMs) to reduce emissions. The government retains all credits/allowances that are issued and uses them to co-finance policy implementation. Governments generally have a broad range of policy options at their disposal, such as energy/ $/ \mathrm{CO}_{2}$ taxation, mandatory efficiency standards, renewable feed-in tariffs or other forms of financial support (Gupta et al. 2007). As no trading units are issued to individual installations, emissions could be accounted at the aggregate sectoral level based on statistical data such as fuel statistics, which reduces transaction costs.

The reduction of transaction costs entailed by accounting for emissions at an aggregate level may facilitate the participation of countries that have not been able to participate in the CDM, which has partly been caused by the substantial installation-level MRV required under the mechanism. Some analysts also consider that implementing PAMs might be easier for poorer countries than trying to attract individual investment projects (Sugiyama, Yamaguchi \& Yamagata, 2005).

Environmental effectiveness, economic efficiency and incentives for private sector participation would strongly depend on what PAMs are implemented. Some policies such as banning outdated technology can achieve very considerable emission reductions at very low transaction costs (Schneider and Cames, 2009). This government-led approach could also facilitate the blending of carbon finance from the NMM with other sources of domestic or international climate finance (Prag and Briner, 2012). 
In option 2, the government would pass the sectoral target on to the individual installations within the sector. Each installation would be assigned its own emission target. If an installation achieves its target, it receives credits. If not, there are no penalties.

Hence, installations would be directly exposed to the carbon price signal. The regulatory risk for investors would be much lower than under the CDM as there would be no question about eligibility, which would be determined top-down, and thus sectoral crediting might even be able to actually drive financing decisions (Marcu, 2009).

However, since target achievement would not be mandatory for installations, there may be situations where some individual installations successfully reduce emissions but others do not and thus the sector as a whole does not. Therefore, the sector as such would not be eligible for credits but individual installations would be. If installations that reduce emissions run the risk of not being rewarded because of the failures of others, the system would hardly provide an incentive to reduce emissions. The crediting of individual installations would need to be decoupled from the performance of the sector as a whole.

The literature discusses various options (e.g. Baron, et al. 2009; Helme et al., 2010; Marcu, 2009; Harrison et al., 2011). One option would be for the host country government to take on the risk and guarantee to provide credits to installations that reduce their own emissions regardless of the overall sector performance. However, this does not reduce the risk, it merely shifts it from the installations to the host country government, which may not have much appetite for assuming such risks, so political feasibility of this option may be low. Another option, which might be politically more acceptable to developing countries, would be to hold back a share of the credits issued to form a reserve. The government could also try to reduce the risk of sectoral non-performance by implementing additional policies to reduce sectoral emissions (that is, combining options 1 and 2). But if both government and 
installation operators work to reduce emissions, the question is who of them deserves which share of the credits for the overall sectoral reduction.

The most straightforward approach may be option 3, to make the installation-level targets mandatory with penalties attached. These could either be financial penalties, which could be used by the government to purchase trading units if needed, or obliging the companies themselves to purchase trading units if they have excess emissions. The government could also introduce a fully-fledged emissions trading system. Option 3 would ensure that each installation has an incentive to reduce emissions and would provide high environmental certainty. However, as regards political feasibility affected companies may be expected to strongly resist the imposition of mandatory targets.

If the sectoral target is passed on to the installation level (options 2 and 3), emissions accounting will also need to be done at installation level, which would significantly increase administrative complexity and the lead-time for implementation. ButzengeigerGeyer et al. (2010) consider that national implementation even in the base case (option 1) is likely to take at least three years. If implementation is done on an installation basis, national implementation would in their view require an additional one to two years.

It bears noting that the above are prototypical options, in reality one can expect a combination of option 1 with option 2 or 3 , as there will always be some policies already in place and further ones are likely to be introduced in parallel or later for climate- or nonclimate reasons, such as air quality. If designed effectively, such a hybrid of emission pricing and other PAMs arguably also provides the best prospect for maximising both environmental effectiveness and economic efficiency. Systems based only on emission prices can be expected to perform well on a short-term basis (static efficiency) but entail a risk that the focus of action is laid on short-term rather than long-term considerations (thus 
neglecting dynamic efficiency). For example, new technologies may be neglected which in their infancy have high costs but may ultimately become the most cost-effective option (Weber and Hey, 2012). This is exemplified by the CDM, which has thousands of hydro and wind energy but only few solar energy projects (UNEP Risø, 2014). At the same time, targeted support instruments such as feed-in tariffs have induced strong deployment and technological learning that has reduced equipment costs of solar photovoltaics by about 80\% within the last five years (Liebreich, 2013). Effectively reducing emissions therefore requires a portfolio of policies tailored to fit the specific circumstances (Gupta et al. 2007).

\subsection{Element 3: Emissions Accounting}

\subsubsection{System Boundaries}

Systems may cover entire sectors, all activities above a certain size threshold or only certain technologies or processes. Determining the coverage is mostly a matter of optimisation between environmental effectiveness, economic efficiency and administrative burden. Broad coverage facilitates broad emission reductions, reduces the potential for intra-sectoral leakage, and promotes economic efficiency since a wider range of mitigation options with variable abatement costs will be available (Schneider and Cames, 2009). However, it also increases administrative requirements.

\subsubsection{Establishment of Reference Levels}

Reference levels may be defined in absolute amounts of emissions or as emissions indexed to economic indicators, such as GDP, tonnes of production etc. (also often referred to as relative or intensity targets). A third option is to set technology targets (see e.g. Schneider and Cames, 2009; Baron et al., 2009).

Compared to the other options, absolute targets are relatively easy to administer but involve relatively large uncertainties due to the difficulty in predicting emission levels. Therefore, they entail a significant risk of over- or under-crediting. Many developing 
countries rely heavily on manufacturing and commodities, which are more sensitive to economic fluctuations than service sectors. As such, growth rates are even more variable and difficult to predict in developing than in industrialised countries (Ellis and Moarif, 2009; Helme et al., 2010). Due to these uncertainties absolute targets may also be politically unacceptable to many host countries, which may be afraid of stipulating too high levels of ambition. Finally, they lack the flexibility to respond to changes in emissions that are not attributable to mitigation action, such as recessions, as currently experienced in the EU ETS.

Indexed targets have the advantage of a lower uncertainty as key emission drivers are factored into the target. Hence, they entail a lower risk of over- and under-crediting and could be politically more acceptable to host countries as they would not become a "cap on growth". However, establishing an acceptable indexed target may be very difficult in complex or diverse sectors where individual installations may have very different levels of carbon intensity. In addition, the target value and resulting credits can only be determined ex-post, once actual output values have been determined, which increases uncertainty for operators and the carbon market. Tying crediting levels to output levels also provides incentives to increase output in order to maximise credit generation. Finally, indexed targets involve higher transaction costs as both emissions and the index need to be monitored.

Technology targets are defined at a certain level of technology diffusion (e.g. MW installed capacity). Setting an appropriate baseline is challenging and always involves a degree of arbitrariness; for technologies in early stages of development it may be impossible. It also is difficult to estimate in advance how a particular technology will actually perform, ex ante emissions estimations are likely to be very approximate. Another disadvantage is the relatively narrow scope. However, this approach is relatively simple to 
administer and may have a higher political feasibility among host countries as it can support their interest to promote or develop specific technologies.

In conclusion, all types of targets have substantial problems. Indexed targets may initially be preferable for rapidly industrialising countries to reduce uncertainties, enhance political acceptability and minimise the risk of over-crediting. However, limiting climate change requires the reduction of absolute emissions. Use of indexed targets should therefore arguably be restricted to an introductory road-testing phase for establishing the mechanism, with a view to ultimately moving to absolute targets.

\subsubsection{The Relationship of CDM and NMM}

A sectoral scheme should ideally cover all installations in a sector in order to prevent intrasectoral leakage. As a result, the scheme could include existing or new CDM projects. This creates issues with leakage and double-counting emission reductions as the same reductions could be counted under the $\mathrm{CDM}$ and the sectoral scheme. Options to address these problems are (see also Aasrud et al., 2009; Butzengeiger-Geyer and Michaelowa, 2009; Schneider and Cames, 2009):

- Carve out CDM projects from the sectoral NMM boundary. This option would be acceptable to project participants and easy to administer. However, there may be risks of intra-sectoral leakage due to shifting of production between CDM projects and the NMM. This risk would apply particularly if new CDM projects would continue to be allowed as investors could choose the scheme that would yield the most credits.

- Do not allow new projects and phase-out existing projects immediately, after their current crediting period or after their last crediting period; and until the phase-out deduct CERs from the sectoral performance. This option would address double- 
counting adequately and be easy to administer. The best option for eliminating leakage would be to immediately phase out $\mathrm{CDM}$ in the sector, but project participants would probably strongly resist such an approach and would have good legal grounds for doing so.

- Continue CDM including new projects and deduct CERs from the sectoral performance. This option would be the most attractive to CDM stakeholders, would be easy to administer and would address double counting well. On the other hand, as in the first option, there would be risks of intra-sectoral leakage and "system shopping" by investors, who could choose the scheme that would yield the most credits, potentially challenging the overall environmental effectiveness.

- Integrate existing CDM projects into a sectoral scheme, e.g. by adapting a CDM benchmark to the benchmark for the sectoral scheme. This option would minimise intra-sectoral leakage, addresses double counting and promotes environmental effectiveness as in contrast to the CDM the NMM aims to achieve net emission reductions. Its acceptability to project participants and administrative feasibility may be lower than the other options and would probably depend on each specific case.

In summary, from the environmental perspective new CDM projects within the sectoral boundary should not be allowed to prevent "system shopping" and credits issued to existing projects should be deducted from the sectoral performance. Phasing out existing $\mathrm{CDM}$ projects before the end of their last possible crediting period might be environmentally beneficial but would be politically difficult and the project participants could be expected to mount legal challenges against such a decision. 


\subsection{Element 4: National Governance Framework}

National institutions would need to fulfil several functions, including establishment of the scheme and its submission for international approval, trading regulation, issuance of trading units, verification and stakeholder involvement (for more details see e.g. Aasrud et al., 2010; Schneider and Cames, 2009). There are two broad options for governing institutions.

Entrusting a government body with management of the scheme is likely to entail few political barriers and medium transaction costs as it could be done by an existing government agency. However, as host country governments have an incentive to maximise credit generation there are likely risks of baseline inflation, setting weak targets, and weak monitoring. Several Annex I countries (Greece, Bulgaria, Romania, Ukraine and Lithuania) have in the past been temporarily barred from using the Kyoto mechanisms due to the low quality of their emissions accounting (UNFCCC, 2013b).

Governance by an independent agency beyond government control, similar to a central bank, would hence be recommendable to promote environmental effectiveness. However, establishing a new agency involves higher transaction costs and host country governments would likely want to retain control of the NMM due to the substantial economic impacts that it could be expected to have. Moreover, setting international rules for national governing agencies would probably come into conflict with sensibilities of host countries regarding their national sovereignty.

In summary, the environmentally preferable option, an independent regulator, may be politically infeasible. To limit perverse incentives it would be recommendable to at least set criteria for national institutions that ban self-regulation and political influence by the regulated entities on the regulator. 


\subsection{Element 5: International Governance Framework}

The central issue for international governance is the competence for approval of national proposals and issuance of credits. Options are:

- The competence of the CDM Executive Board may be extended to cover approval of proposals under the NMM. The Board would take approval decisions on its own based on COP guidance, similar to the process for registering CDM projects.

- The approval mandate may be given to a new supervisory body, similar to how the CDM Executive Board registers projects.

- Sectoral proposals could be approved by the COP, potentially on the basis of the assessment by a regulatory body (which may be the CDM Executive Board or a new body).

Regulating emission markets is a particular challenge since emission units do not have an inherent value. Thus, emission markets mostly lack the competition of interests between buyers and sellers over product quality that helps other markets to self-regulate to some extent. In emission markets, both buyers and sellers have a common interest to maximise the volume of emission units. As such, there is a strong case for entrusting regulation to an entity that is independent of governments, which could theoretically be achieved by the first two options. Technically, the first two options are essentially the same. The case for a new body is mostly political, given that the CDM is a mechanism of the Kyoto Protocol while the NMM is to be established under the Convention.

However, whether such a body would indeed be independent would strongly depend on its composition. The CDM Executive Board consists of political candidates nominated by the UNFCCC's regional groups. Fues et al. (2008) find that as a result decisions are 
substantially influenced by political-economic variables. In particular, Board membership of the country or countries involved in a project raises the chance of approval. A body composed of full-time professionals might be less subject to being influenced by countries' special interests. However, in terms of political feasibility Parties may want to have a body similar to the CDM Executive Board to facilitate continuous political oversight.

Another consideration is that setting sector-wide emission targets is a rather political question and might not be appropriate for a technical body. One may doubt whether in particular large countries such as China or India would be willing to have the adequacy of their proposals determined by some supervisory body. Therefore, approval by the COP may be the politically more adequate option. Such COP decisions would nonetheless probably have to be based on an assessment by the regulatory body since the COP would hardly be in a position to assess the technical details of baselines and MRV systems by itself. One may also doubt whether the COP would be able to process the potentially large number of sectoral proposals in a timely manner.

For the assessment of sectoral proposals, the options include a CDM-like model based on auditing companies or a process similar to the Annex I inventory review model: assessment by independent experts coordinated by the Secretariat. There is strong criticism on the fact that the CDM auditors are selected and paid for by the project participants, which leads to an inherent conflict of interest. A similar situation with respect to credit rating agencies is often cited as one factor that contributed to the financial crisis (de Sépibus and Tuerk, 2011). It also should be noted that the CDM Executive Board has deemed it necessary to partly replicate the work of the auditors by two further layers of scrutiny by the Secretariat and by a review and issuance team (RIT), which is a team of external experts that assist the Board in assessing projects. The RIT is in general terms 
comparable to the roster of experts which the Secretariat draws on for the in-depth reviews of Annex I inventories.

In summary, again the environmentally preferable option, regulation by an independent body, is probably politically infeasible. Maintenance of impartiality may thus have to rely on provisions for transparency and stakeholder involvement. As for the detailed technical assessment of proposals, assessment teams should not be paid by NMM participants to prevent conflicts of interest. Therefore, the Annex I inventory review model seems preferable to the CDM model.

\section{Insights from Country Showcases}

The following examines NMM feasibility in four sectors in five developing countries: the power sector in Chile and South Africa, the steel sector in Brazil, the refineries sector in Indonesia and the cement sector in Vietnam. The most important criterion in the selection of sectors and countries was the availability of data on emission sources, sectoral emission levels, abatement costs and national policies. In addition, the aim was to include different sectors in different geographies.

The underlying research was conducted as desk studies based on publicly available information. It had two main objectives. The first objective was to identify whether there is sufficient reliable data available to perform the detailed emissions accounting that is required for a mechanism based on the use of tradable emission units. For this purpose the national communications were analysed and experts were consulted to determine the availability of further data. The second objective was to identify what impact the NMM could have in the respective country/sector contexts. This is a question of the size and cost of the available mitigation potential and of whether there exist substantial non-price barriers to investment, such as non-competitive market structures. To answer these 
questions the research surveyed publicly available information on the available mitigation potential, mitigation costs and sectoral market conditions.

\subsection{Data Availability and Consistency}

Consistent and reliable data on emissions from installations in a specific sector is crucial for the design and successful operation of the NMM. Such data is not always available. The national communications do not always provide sufficient information on emissions at the sector level. In addition, in most national communications the data is not current and is available only up until 2000 or 2005 , at the latest. However, this situation will probably improve soon due to the implementation of the stricter reporting requirements stipulated in the Cancún Agreements. There may also be more information available nationally than is reflected in the UNFCCC reporting. Nonetheless, without external review it is unclear whether such undisclosed data, if it exists, is more accurate than the publicly available data.

Cross-checking the national communications with other data sources in some cases revealed inconsistencies. For Chile, while the second national communication puts national 2006 emissions at about 59.6 Mt $\mathrm{CO}_{2}$-eq. (Chile 2011), a study from the University of Chile puts 2006 emissions at more than $63 \mathrm{Mt} \mathrm{CO}_{2}$-eq. (O'Ryan et al.). For Indonesia, the second national communication reports 2005 emissions of about $135 \mathrm{Mt}$ from electricity generation, petroleum and gas refining (Indonesia 2010), while a study from the National Council on Climate Change puts 2005 emissions at $110 \mathrm{Mt} \mathrm{CO}_{2}$-eq. for electricity generation and an additional $91 \mathrm{Mt} \mathrm{CO}_{2}$-eq. for petroleum and gas refining (DNPI 2010).

In all cases, it therefore seems that targeted and detailed sector-specific studies are needed before an NMM could be successfully implemented. These conclusions are in line with earlier studies, which have also identified data availability and quality as a key bottleneck 
in many countries (e.g. Butzengeiger-Geyer et al., 2010; Helme et al., 2010; Cai et al., 2012).

\subsection{Abatement Costs and Carbon Price}

The NMM aims to expose sectors to a carbon price, which creates a financial incentive for investments in emission reductions. The research found that at moderate carbon prices as are currently prevailing, only a few abatement options are made financially feasible in addition to what is already feasible without a carbon market incentive. The research also showed that many abatement options may be economically profitable even without a carbon price, which would cast doubt on the potential of price-based instruments to effectively incentivise these options. The results need to be taken with a grain of salt, given the limitations of data availability and quality noted in the previous section, but the general direction should be valid.

In Indonesia and Vietnam most abatement potential actually appears to be profitable even without a carbon price. In Indonesia, according to DNPI (2010), energy efficiency, improved maintenance and similar measures could reduce 2030 emissions from refineries by ca. $13.5 \%$ below BAU levels at profits of around $70 \mathrm{USD} / \mathrm{tCO}_{2}$-eq. and more. Similar volumes of reductions could be achieved by the installation of cogeneration at refineries that are using waste heat at a cost of only $6 \mathrm{USD} / \mathrm{tCO}_{2}$-eq. For Vietnam, IGES and TERI (2011) estimate that cement sector emissions could be reduced by ca. $15 \mathrm{Mt} \mathrm{CO}_{2}$-eq. by 2020 at negative costs through the substitution of clinker with fly ash, fuel switch to gas and biomass, and cogeneration.

South Africa also has substantial no-regret and low-cost mitigation potential according to the official Long-Term Mitigation Scenarios study, which estimated reduction potential over the period 2003-2050. The study also estimated associated mitigation costs relating to 
different assumptions on discount rates, with 10\% used as central case (costs are given in Rand in the study, here translated into USD at current exchange rates). The potential of commercial energy efficiency is estimated at on average $8 \mathrm{Mt} \mathrm{CO}_{2}$-eq. per year, at mitigation costs of about -22 USD/t. Estimated mitigation costs of industrial and residential efficiency are also negative but figures are not differentiated according to types of energy used. Average annual $\mathrm{CO}_{2}$ savings from increasing the share of renewable electricity to $27 \%$ by 2050 are estimated at $42 \mathrm{Mt} \mathrm{CO}_{2}$-eq. at costs of about $6 \mathrm{USD} / \mathrm{t}$ without assuming technological learning, and at $57 \mathrm{Mt} \mathrm{CO}_{2}$-eq. at costs of $-16 \mathrm{USD} / \mathrm{t}$ when assuming technological learning. Increasing the renewable electricity share to $50 \%$ by 2050 leads to an estimated $68 \mathrm{Mt} \mathrm{CO}_{2}$-eq./yr, at costs of about $10 \mathrm{USD} / \mathrm{t}$ without and about $0.33 \mathrm{USD} / \mathrm{t}$ with learning. The reduction potential of "cleaner coal" is estimated at $3 \mathrm{Mt}$ $\mathrm{CO}_{2}$-eq./yr at costs of about $-0.33 \mathrm{USD} / \mathrm{t}$ (Hughes et al. 2007).

According to McKinsey (2010), the Brazilian steel sector has a no-regret energy efficiency and coke substitution potential of about $6.5 \mathrm{Mt} \mathrm{CO}_{2}$-eq. in 2030 but the vast majority of the abatement potential (35 Mt $\mathrm{CO}_{2}$-eq.) comes at a price of over $20 \mathrm{EUR} / \mathrm{t} \mathrm{CO}_{2}$-eq., through the introduction of more efficient machinery and processes or carbon capture and storage (CCS). Also in Chile the no-regret potential is small. O'Ryan et al. (2010) see $4 \mathrm{Mt}$ $\mathrm{CO}_{2}$-eq. of mitigation potential from new hydropower by 2030 at a cost of $-32 \mathrm{USD} / \mathrm{t}$, but about $32 \mathrm{Mt} \mathrm{CO}_{2}$-eq. from other renewables, nuclear power and CCS at costs of 19 to 65 $\mathrm{USD} / \mathrm{t} \mathrm{CO}_{2}$-eq. The international carbon price would need to increase substantially above current levels to make these technologies financially feasible.

\subsection{Sectoral Market Readiness}

In a well-functioning market, investments that represent financially viable options would be developed to reduce the costs of production. That existence of 'no-regret' potential suggests that there are some 'non-price barriers', or 'hidden costs'. 
A relevant factor is probably that most of the sectors considered are either state-owned or have highly concentrated private ownership. In Chile, in the two most important regional grids, $90 \%$ and $95 \%$ of the respective generation capacity is under the control of three holding companies (IEA, 2009). In Indonesia, the majority of the country's refining capacity is controlled by a single state-owned entity, Pertamina (PricewaterhouseCoopers, 2012). In South Africa, electricity production is basically a state-owned monopoly, with Eskom producing about 96\% of the electricity (South Africa, 2011). The Vietnamese cement sector is being transferred from a centrally-planned, state-run enterprise into a market economy with different players. However, the state-owned Vietnamese Cement Industry Corporation (VICEM) still controls most of the industry (Edwards, 2012).

This state dominance in three of the five cases may limit the ability of installation operators to make commercial choices and react to the market incentives which the NMM aims to provide. For the South African case this is confirmed by Goldblatt (2011), who argues that, "it is apparent that the existence of concentrated energy supply markets, monopoly power in electricity generation, and a small number of liquid fuels refineries impose serious concerns about the ability to construct a competitive, liquid and efficient emissions trading market.”

A price-based mechanism, such as an NMM, can help to overcome such non-price barriers by offering an incentive to address them and increasing financial benefits to help overcome hidden costs. Nonetheless, effective removal of non-price barriers usually also requires application of dedicated policy instruments that directly address those barriers (Gupta et al., 2007). The sale of tradable units from the NMM could provide revenues for the development of policies that remove non-price barriers. 
However, the government would accrue international revenue from sale of surplus units only once emissions have been successfully reduced, while it would incur the cost of removing non-price barriers ex ante. Carbon market finance might therefore need to be blended with other sources of finance, for example in the form of nationally appropriate mitigation actions (NAMAs) supported by industrialised countries. In addition, the government could source domestic revenues if it used domestic price-based instruments to achieve the NMM target, such as carbon taxation or a domestic emission trading system with auctioning.

\section{Conclusions}

This article aimed to identify key design options for the NMM based on a survey of the literature and to assess what options would be best suited to maximise environmental effectiveness and integrity as well as economic efficiency. Furthermore, potential application of the NMM was analysed for five country-sector combinations.

While there often are trade-offs, several design options recommend themselves for maximising mitigation outcomes and economic efficiency. Where administratively feasible broad coverage facilitates large-scale emission reductions, reduces the potential for intrasectoral leakage, and promotes economic efficiency since a wider range of mitigation options with variable abatement costs will be available. Starting with indexed instead of absolute targets may help to enhance political acceptability and minimise the risk of overcrediting. However, as limiting climate change requires the reduction of absolute emissions, use of indexed targets should arguably be restricted to an introductory roadtesting phase for establishing the mechanism. Keeping crediting/trading periods short helps to avoid long-term lock-in of low ambition. While politically difficult, establishing independent governance bodies nationally and internationally would be recommendable as 
emission reductions have no inherent economic value and NMM participants have hence no inherent economic interest to safeguard environmental integrity. New CDM projects should not be allowed within NMM boundaries and credits issued to existing projects should be deducted from the sectoral performance in order to prevent double counting and "system shopping”.

The timeline for implementing the NMM is likely to be relatively long, even once agreement under the UNFCCC has been reached. The NMM will be a new instrument and substantial data is needed to assess the possible impact of the NMM on a sector, determine an appropriate target, and to divide the target among installations. As noted, one study estimated lead times of up to 5 years (Butzengeiger-Geyer et al., 2010). The assessment of five specific country-sector combinations in this article confirms that availability and reliability of data is indeed often a key barrier. While there may be more information available within governments, without external review it is unclear whether such undisclosed data, if it exists, is more accurate than the publicly available data.

The mechanism would probably have to be operated by the host country government as private entities could hardly take responsibility for entire sectors. The host countries' operational framework would therefore be key for the constitution of actual emission reduction incentives. A hybrid of emission pricing and other policies and measures arguably provides the best prospect for maximising both environmental effectiveness and economic efficiency. Systems based only on emission prices can be expected to maximise short-term economic efficiency but entail a risk of neglecting long-term considerations.

In addition, a sector may not be receptive to carbon price incentives at the moment as either the incentives to improve the efficiency of operations or the means to do so may be lacking, for example due to the existence of monopolies/oligopolies. The investigation of 
the five country-sector combinations showed that according to the existing data there seems to be a large commercially viable abatement potential that is left untouched. This situation indicates the existence of strong non-price barriers or hidden costs, which would first have to be addressed before an NMM could have the intended impact. While pricebased mechanisms can help to overcome non-price barriers by offering an incentive to address them and increasing financial benefits, effective removal of non-price barriers usually also requires application of dedicated policy instruments.

In the short term, strengthening an existing and successful policy could be an effective approach for countries where market-based mechanisms are unlikely to be able to incentivise mitigation action in the current sector conditions. If certain policies, like sector reform, have demonstrated to have the intended effect, the NMM can support the upscaling of these policies. For example, if a government has a preferential feed-in tariff for power generated with renewables, the NMM could help provide the financial means to increase the price differential with power from fossil sources or the scope of the policy, either in terms of more expensive technologies or in terms of volume. A practical example is the "GET FiT Uganda " programme, whereby an existing but commercially unattractive FIT is "topped up" by international donors (GET FiT Uganda Website).

Puhl (2011) suggests a concept for the integration of an FIT with carbon finance. The concept is based on the situation in Thailand, which introduced an FIT in 2005 and consequently saw a rapid increase of the share of renewable electricity from originally about $6 \%$ to about $14 \%$ in 2012 . The cost of this policy has been borne by consumers and tax payers, which has led to strong political pressure to reduce these costs. Co-funding with carbon market revenue would reduce the national cost impact of the policy and thus allow its further up-scaling. Such a system would require less preparation than an entirely new programme because the institutional capacity is already largely in place. 
Major additional insights could be gained by carrying out one or more real-world pilots for implementing an NMM. Such pilots could seek to take existing approaches like Thailand's FIT as starting point and should ideally generate tradable and compliance-grade emission credits in order to fully simulate the real-life conditions of an NMM. The generation of compliance-grade credits would probably also be necessary to achieve participation by private companies, as was the case in the World Bank's Prototype Carbon Fund.

However, as actual demand for additional credits is currently very low, pilots could alternatively be developed as supported NAMAs, but with carbon market-level MRV and the perspective to translate the supported NAMAs into a market-based approach in the mid-term. To simulate market operations, such pilots could generate non-compliance credits to be purchased by the funding organisations or governments. Such an approach would be akin to results-based finance models which have been developed in international development cooperation, of which the GET FiT Uganda programme is one example, and the potential of which for climate finance is now being explored (see e.g. Kossoy et al., 2013).

\section{Acknowledgements}

This article is based on research supported by the European Commission, DirectorateGeneral for Climate Action, under grant number CLIMA.B.3/SER/2011/0029. 


\section{References}

Allan, J., et al., 2013, Summary of the Warsaw Climate Conference: 11-23 November 2013, Earth Negotiations Bulletin, Vol. 12, No. 594, Tuesday 26 November 2013. International Institute for Sustainable Development.

Aasrud, A., Baron, R., Buchner, B., McKall, K., 2009, Sectoral Market Mechanisms: Issues for Negotiation and Domestic Implementation. Paris: Organisation for Economic Cooperation and Development and International Energy Agency.

Aasrud, A., Baron, R., Karousakis, K., 2010, Market Readiness: Building Blocks for Market Approaches. Paris: Organisation for Economic Cooperation and Development and International Energy Agency.

Baron, R., Buchner, B., Ellis, J., 2009, Sectoral approaches and the carbon market. Paris: Organisation for Economic Cooperation and Development and International Energy Agency.

Bloomberg, 2013, South Korea's Emission Trading Scheme, White Paper. Bloomberg New Energy Finance.

Boemare, C., Quirion, P., 2002, 'Implementing Greenhouse Gas Trading in Europe: Lessons from Economic Literature and International Experiences', Ecological Economics, $43(2-3), 213-230$.

Bolscher, H., van der Laan, J., Slingerland, S., Sijm, J., Bakker, S., Mikunda, T., Wehnert, T., Sterk, W., Hoogzaad, J., Wemaere, M., Conway, D., 2012, Design options for sectoral carbon market mechanisms, Final Report. Rotterdam: Ecorys. 
Butzengeiger-Geyer, S., Castro, P., Dransfeld, B., Michaelowa, A., Okubo, Y., Skogen, A., Tangen, K., 2010, New Market Mechanisms in a Post 2012 Climate Regime - Challenges and Opportunities, Report to the German Federal Environment Agency. Universität Zürich, perspectives climate change, PointCarbon.

Butzengeiger-Geyer, S., Michaelowa, A., 2009, Interaction between CDM and new sectoral approaches - avoiding double-counting, Background paper to the report: Butzengeiger-Geyer, S., Castro, P., Dransfeld, B., Michaelowa, A., Okubo, Y., Skogen, A., Tangen, K. (2010): New Market Mechanisms in a Post 2012 Climate Regime - Challenges and Opportunities, Report to the German Federal Environment Agency. Universität Zürich, perspectives climate change, PointCarbon.

Cai, W., Wang, C., Chen, J., Wang, S., 2012, 'Sectoral Crediting Mechanism: How Far China Has to Go', Energy Policy, 48, 770-778.

Chile, 2011, Segunda Comunicación Nacional de Chile ante la Convención Marco de las Naciones Unidas sobre Cambio Climático. Santiago: Gobierno de Chile, Ministerio del Medio Ambiente.

De Sépibus J., Tuerk A., 2011, 'New Market-Based Mechanisms Post 2012: Institutional Options and Governance Challenges When Establishing a Sectoral Crediting Mechanism', Environmental Liability, 19(4), 111-130.

DNPI, 2010, Indonesia's greenhouse gas abatement cost curve, August, 2010. Dewan Nasional Perubahan Iklim (National Council on Climate Change), Indonesia.

Edwards, P., 2012, “Cement in Vietnam”, Global Cement Magazine, Thursday 19 April 2012 [available at: http://www.globalcement.com/magazine/articles/687-cement-invietnam]. 
EEA, 2013, Trends and projections in Europe 2013 - Tracking progress towards Europe's climate and energy targets until 2020, EEA Report No. 10/2013. Copenhagen: European Environment Agency.

Ellis, J., Moarif, S., 2009, GHG Mitigation Actions: MRV Issues and Options. Paris: Organisation for Economic Cooperation and Development, International Energy Agency.

Fues, F., Michaelowa, A., Michaelowa, K., 2008, UN approval of greenhouse gas emission reduction projects in developing countries: The political economy of the CDM Executive Board. Zurich: University of Zurich and Center for International and Comparative Studies (CIS).

GET FiT Website, http://www.getfit-uganda.org/.

Goldblatt, M., 2010, 'A comparison of emission trading and carbon taxation as carbon mitigation options for South Africa', in: Winkler, H., Marquard, A., Jooste, M. (Eds.), Putting a Price on Carbon: Economic Instruments to Mitigate Climate Change in South Africa and Other Developing Countries, Proceedings of a Conference held at the University of Cape Town, 23 - 24 March 2010 (pp. 181-195). Cape Town: Energy Research Centre, University of Cape Town.

Gupta, S., et al., 2007, "Policies, Instruments and Co-operative Arrangements". In Metz, B., et al. (Eds.), Climate Change 2007: Mitigation. Contribution of Working Group III to the Fourth Assessment Report of the Intergovernmental Panel on Climate Change. Cambridge, New York: Cambridge University Press.

Harrison, D., Lo Passo, F., Radov, D., Nichols, A., Klevnas, P., Foss, A., 2011, Evaluation of Incentives in International Sectoral Crediting Mechanisms: A Report for Enel. Boston, Rome: NERA Economic Consulting. 
Haya, B., 2009, Measuring Emissions Against an Alternative Future: Fundamental Flaws in the Structure of the Kyoto Protocol's Clean Development Mechanism. Berkeley, CA: Energy and Resources Group, University of California at Berkeley.

Helme, N., Whitesell, W., Houdashelt, M., Osornia, J, Ma, H., Lowe, A., Polzin, T., 2010, Global Sectoral Study: Final report .Washington, DC: Center for Clean Air Policy.

Hughes, A., Haw, M., Winkler, H., Marquard, A. Merven, B., 2007, Energy Modelling: A modelling input into the Long Term Mitigation Scenarios process, LTMS Input Report 1, October 2007. Cape Town: Energy Research Centre, University of Cape Town.

IEA, 2009, Chile: Energy Policy Review 2009. Paris: Organisation for Economic Cooperation and Development and International Energy Agency.

IGES, 2011, Possible elements of market-based mechanisms: A summary of views from Parties on the elaboration of market-based mechanisms under post-2012 regime. Hayama: Institute for Global Environmental Strategies.

IGES \& TERI, 2011, IGES \& TERI CDM Reform Paper: Linking Ground Experience with CDM Data in the Cement Sector in India. Hayama and New Delhi: Institute for Global Environmental Strategies and The Energy and Resources Institute.

Indonesia, 2010, Indonesia Second National Communication Under The United Nations Framework Convention on Climate Change (UNFCCC). Jakarta: Ministry of Environment, Republic of Indonesia.

Kossoy, A., Guigon, P., 2012, State and Trends of Carbon Market 2012. Washington, DC: World Bank. 
Kossoy, et al, 2013, Mapping Carbon Pricing Initiatives: Developments and Prospects 2013. Washington, DC: World Bank.

Liebreich, M., 2013, Keynote. Bloomberg New Energy Finance Climate Summit. 23 April 2013. http://bnef.folioshack.com/document/summit2013/1czp7t.

Marcu, A., 2009, 'Sectoral Approaches in Greenhouse Gas Market: A Viable Proposition?', in: Holm Olsen, K., Fenhann, J., Hinostroza, M. (eds.), NAMAs and the Carbon Market, Nationally Appropriate Mitigation Actions of Developing Countries (pp. 97-111). Roskilde: UNEP Risø Center.

McKinsey, 2010, Pathways to a low carbon economy for Brazil. Sao Paolo: McKinsey\&Company.

Meckling, J., Chung, G., 2009, 'Sectoral approaches for a post-2012 climate regime: a taxonomy', Climate Policy, 9(6), 652-688.

O’Ryan, R., Diaz, M. and Clerc, J., 2010, Energy Consumption, Greenhouse Gas Emissions and Mitigation Options for Chile, 2007 - 2030. Program for Environmental Economics and Management (PROGEA), Department of Industrial Engineering, University of Chile.

Prag, A., Briner, G., 2012, Crossing the Threshold: Ambitious Baselines for the UNFCCC New Market-Based Mechanism. Paris: Organisation for Economic Cooperation and Development and International Energy Agency.

PricewaterhouseCoopers, 2012, Oil and Gas in Indonesia, Investment and Taxation Guide, May $2012-5^{\text {th }}$ edition. PricewaterhouseCoopers. 
Puhl, I., 2011, Linking Domestic Incentives (feed-in-tariff) with Carbon Market Mechanisms and NAMA to Deliver Renewable Energy at Scale. Presentation, Durban, 5 December 2011.

Samaniego, J., Figueres, C., 2002, 'Evolving to a Sector-Based Clean Development Mechanism', in:Baumert, K. (ed.), Building on the Kyoto Protocol: Options for Protecting the Climate (pp. 89-108). Washington, DC: World Resources Institute.

Schneider, L., 2009, 'Assessing the additionality of CDM projects: practical experiences and lessons learned', Climate Policy, 9(3), 242-254.

Schneider, L., Cames, M., 2009, A Framework for a Sectoral Crediting Mechanism in a Post-2012 Climate Regime: Report for the Global Wind Energy Council. Berlin: OekoInstitut, Institute for Applied Ecology.

Schmidt, J., Helme, N., Lee, J., Houdashelt, M., 2008, 'Sector-based approach to the post2012 climate change policy architecture', Climate Policy, 8(5), 494-515.

Spalding-Fecher, R., Achanta, A. N., Erickson, P., Haites, E., Lazarus, M., Pahula, N., Pandey, N., Seres, S., Tewari, R., 2012, Assessing the Impact of the Clean Development Mechanism, Report Commissioned by the High-Level Panel on the CDM Policy Dialogue. Luxembourg: United Nations Framework Convention on Climate Change Secretariat.

South Africa, 2011, South Africa's Second National Communication under the UNFCCC. Pretoria: Department of Environmental Affairs, Republic of South Africa.

Sterk, W.; Wittneben, B., 2006, 'Enhancing the clean development mechanism through sectoral approaches: definitions, applications and ways forward', International Environmental Agreements: Politics, Law and Economics, 6(3), 271-287. 
Sterk W., 2012, Current Proposals and Positions on New Market Mechanisms. Wuppertal: Wuppertal Institute for Climate, Environment and Energy.

Sugiyama, T., Yamaguchi, K, Yamagata, H., 2005, CDM in the Post Kyoto Regime: Incentive mechanisms for developing countries to promote energy conservation and renewable energies. Workshop Issue Paper, March 22 and 23, 2005.

The Gold Standard, 2012, The Gold Standard Toolkit, Version 2.2. http://www.cdmgoldstandard.org/wp-content/uploads/2012/06/GSv2.2_Toolkit.pdf.

UNEP Risø, 2014, UNEP Risoe CDM/JI Pipeline Analysis and Database, May 1st 2014. http://cdmpipeline.org/.

UNFCCC, 2002, Modalities and procedures for a clean development mechanism, as defined in Article 12 of the Kyoto Protocol, Decision 17/CP.7, FCCC/CP/2001/13/Add.2. Bonn: United Nations Framework Convention on Climate Change Secretariat.

UNFCCC, 2005, Executive Board of the Clean Development Mechanism, Twenty-Second Meeting, Report, Annex 3, Clarifications on the Consideration of National and/or Sectoral Policies and Circumstances in Baseline Scenarios (Version 02). Bonn: United Nations Framework Convention on Climate Change Secretariat.

UNFCCC, 2011, Ad Hoc Working Group on Long-term Cooperative Action under the Convention, Views on the elaboration of market-based mechanisms, Submissions from Parties, FCCC/AWGLCA/2011/MISC.2. Bonn: United Nations Framework Convention on Climate Change Secretariat. 
UNFCCC, 2012a, Outcome of the work of the Ad Hoc Working Group on Long-term Cooperative Action under the Convention, Decision 2/CP.17, FCCC/CP/2011/9/Add.1. Bonn: United Nations Framework Convention on Climate Change Secretariat.

UNFCCC, 2012b, Ad Hoc Working Group on Long-term Cooperative Action under the Convention, Views on a new market mechanism, Submissions from Parties, FCCC/AWGLCA/2012/MISC.6, and addenda 1-6. Bonn: United Nations Framework Convention on Climate Change Secretariat.

UNFCCC, 2012c, Technical Paper established by the Secretariat on "Various approaches, including opportunities for using markets, to enhance the cost-effectiveness of, and to promote, mitigation actions, bearing in mind different circumstances of developed and developing countries”, FCCC/TP/2012/4. Bonn: United Nations Framework Convention on Climate Change Secretariat.

UNFCCC, 2013a, Agreed outcome pursuant to the Bali Action Plan, Decision 1/CP.18, FCCC/CP/2012/8/Add.1. Bonn: United Nations Framework Convention on Climate Change Secretariat.

UNFCCC, 2013b, Questions of Implementation. Bonn: United Nations Framework Convention on Climate Change Secretariat Website, http://unfccc.int/kyoto_protocol/ compliance/questions_of_implementation/items/5451.php.

Ward, M., Streck, C., Winkler, H., Jung, M, Hagemann, M., Höhne, N., O’Sullivan, R., 2008, The Role of Sector No-Lose Targets in Scaling Up Finance for Climate Change Mitigation Activities in Developing Countries, Prepared for the International Climate Division, Department for Environment, Food and Rural Affairs (DEFRA), United Kingdom. 
Weber, M., Hey, C., 2012, "Effektive und effiziente Klimapolitik: Instrumentenmix, EEG und Subsidiarität”. Wirtschaftsdienst, 92(13), 43-51.

Yamin, F, Depledge, J., 2004, The International Climate Change Regime, A Guide to Rules, Institutions, and Procedures. Cambridge et al.: Cambridge University Press. 